\title{
Gamification in MOOCs to enhance users' goal achievement
}

Citation for published version (APA):

Antonaci, A., Klemke, R., Stracke, C. M., \& Specht, M. (2017). Gamification in MOOCs to enhance users' goal achievement. In Proceedings of 2017 IEEE Global Engineering Education Conference (EDUCON2016): "Challenging the Transition from the Classic to the Emerging in Engineering Education" (pp. 1654-1662). [16946671] IEEE. https://doi.org/10.1109/EDUCON.2017.7943070

\section{DOI:}

10.1109/EDUCON.2017.7943070

Document status and date:

Published: 01/01/2017

Document Version:

Peer reviewed version

Please check the document version of this publication:

- A submitted manuscript is the version of the article upon submission and before peer-review. There can be important differences between the submitted version and the official published version of record. People interested in the research are advised to contact the author for the final version of the publication, or visit the DOI to the publisher's website.

- The final author version and the galley proof are versions of the publication after peer review.

- The final published version features the final layout of the paper including the volume, issue and page numbers.

Link to publication

\section{General rights}

Copyright and moral rights for the publications made accessible in the public portal are retained by the authors and/or other copyright owners and it is a condition of accessing publications that users recognise and abide by the legal requirements associated with these rights.

- Users may download and print one copy of any publication from the public portal for the purpose of private study or research.

- You may not further distribute the material or use it for any profit-making activity or commercial gain

- You may freely distribute the URL identifying the publication in the public portal.

If the publication is distributed under the terms of Article 25fa of the Dutch Copyright Act, indicated by the "Taverne" license above, please follow below link for the End User Agreement:

https://www.ou.nl/taverne-agreement

Take down policy

If you believe that this document breaches copyright please contact us at:

pure-support@ou.nl

providing details and we will investigate your claim.

Downloaded from https://research.ou.nl/ on date: 26 Apr. 2023 


\title{
Gamification in MOOCs
}

\section{to enhance users' goal achievement}

\author{
Alessandra Antonaci, Roland Klemke, Christian M. Stracke \& Marcus Specht \\ Welten Institute \\ Open University of the Netherlands, \\ Heerlen, The Netherlands

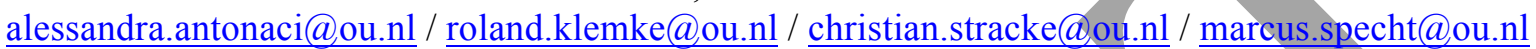

\begin{abstract}
Gamification in engineering education has been applied with success in the last years. Also, Massive Open Online Courses (MOOCs) are recognized as a good strategy to enhance engineering education. Nevertheless, MOOCs have two main weaknesses: first, lack of addressing personal goals; and second, low completion rates in comparison to the number of registrations to the MOOCs. To improve learning experiences in MOOCs and to strengthen self-regulated personalized learning we propose the application of gamification in MOOCs. Our assumption is that MOOC learners will better succeed in achieving their goals if they can individually personalize and plan their learning paths through gamification. This assumption is based on the implementation intention theory which claims that people who foster their goal intentions with implementation intentions are comparatively more successful in their personal goal achievements. Based on a preliminary literature review this article presents and arguments on our research idea on how to apply gamification to enhance MOOC users' goal achievement. Besides, it introduces a new perspective on MOOC completion rates based on the user intention and a new way of measuring it via the Personal Goal Achievement Ratio (PGAR) and the Overall Goal Achievement Ratio (OGAR).
\end{abstract}

Keywords-gamification; goal achievement; user intention; completion rate; MOOC; implementation intention theory

\section{INTRODUCTION}

MOOCs are often criticized for their relatively low completion rates, which has already been questioned as the only relevant measure of quality [1][2][3]. In this paper, we present completion rate related to the learners' original intentions of approaching the MOOC. To enhance completion rate, in the perspective of goal achievement, we propose to apply gamification (a gamified-approach) to MOOCs.

Gamification is the application of game elements in a nongame scenario with the purpose of having an effect and solving a problem [4]. The purpose of this paper is to describe our idea on how gamification elements can be introduced into MOOCs in order to enhance users' goal achievements. More specifically we aim to identify the game elements that will allow MOOC users to implement their intention via the act of planning, based on the implementation intention theory [5], i.e. avoiding an intention behaviour gap [6].

The paper is divided in six sections. Section II, describes gamification: its origin, available frameworks for designing it with their specific aspects and drawbacks. The section is ended by highlighting the needs of further empirical studies. In Section III MOOCs are detailed as our field of application with an emphasis on the problem that we want to address by applying gamification. Especially, new perspectives will be presented on the MOOCs' completion rate and dropout and on the connection among goal achievement, gamification, and MOOCs. In Section IV examples of gamified MOOCs ayailable in the literature are presented. The article concludes by explaining how to address MOOC users' goal achievement by using gamification (Section V) and our conclusions and the future work plan (section VI).

\section{GAMIFICATION}

\section{A. Brief History and definition of Gamification}

The first use of gamification dates back to 1912 when the American Cracker Jack, a popcorn brand, included free surprise toys in its packets as a marketing idea [8]. The scout movement (1910) with their utilization of "ranks" as well as "badges" assigned to children for their achievements, has also been recognized as a form of gamification in education [8] [9]. In the academic field, the first publication on the topic of gamification can be attributed to Thomas Malone, dating back to the 1980s [9].

The term gamification itself is quite recent. In 2002, Nick Pelling, a British game developer, coined and used it to describe his idea of enhancing the enjoyability and the speed of "electronic transactions" with "game-like accelerated user interface design" [8]. An often cited definition of gamification was elaborated by Deterding et al. [4] in 2011 who referred to it as "the use of game design elements in non-game contexts" [4]. According to Nah et al. [10], the most used game design elements in education are Points, Levels, Badges, 
Leaderboards, Prizes and Rewards, Progress Bars, Storyline and Feedback.

Points are the numerical values assigned to the users by the achievement of a goal or a task and completion of a level, as a score they represent numerically the success of the user. They are generally displayed on the leaderboards, which help the user to contextualize his/her performance in comparison to others.

Levels are connected with the commitment a user needs to invest for the achievement of a task. They help a user to perceive their progress. The completion of a level as well as of a task can be displayed on the Progress Bar.

Prizes, badges, and rewards are virtual objects, mostly in the shapes of trophies and cockades assigned to reward a user for the completion of a goal, task, level.

While Feedback is information that (generally) the system sends to users for their performance. Different types of feedbacks are available in accordance with Mazarakis [11]: "gratitude feedback", when the system thanks a user for the participation; "historical feedback", that gives back information about user performance within the time the application has been used; "relative ranking feedback", which informs users about the points reached by completing a determinate task or goal; "social ranking feedback", gives the user information related to his/her points in relation to another participant; and "wrong/right" which informs a user about the accuracy of his/her performance and/or answer [11].

Last but not least, the game element storyline, also narrative, consists in the art of telling a story in order to contextualize e.g. the learning content in a meaningful and logical environment. If a narrative is applied in a learning scenario, it provides users with "opportunities for reflection, evaluation, illustration, exemplification, and inquiry" [12].

Although gamification is successfully being applied in engineering education [13][14][15] and its potential as motivator and engagement mean are claimed by several authors [16], more empirical studies are needed. Generally, gamification (especially applied in engineering education) is still a young discipline [17], which offers a vast variety of approaches and means. Consequently, among other needs, a clearer understanding of the effects that specific aspects of gamification generate on users' behavior is required.

Gamification is more than the application of game elements in a non-game scenario: the mere implementation of those elements does not guarantee a result. The choice of the game elements and their design needs to be related to the problem to be solved and the population targeted [7].The next subsection presents a brief review of the literature on gamification design frameworks.

\section{B. Design Gamification}

In literature, several strategies have been reported with a particular focus on frameworks to design gamification. They are based on game principles, offering guidance for designing gamified activities. This section discusses some of these frameworks but also underlines that even if different frameworks are available, their validity has often not been proven empirically yet.

Mora et al. [18] identify and analyze a total number of eighteen frameworks for gamification design. Their analysis is based on nineteen items clustered into the following five categories: economic; logic; measurement; psychology and user interaction. As results, they report (1) about the development and flourishment of the frameworks to design gamification; and (2) on the most used approaches. The first ones date back to 2013 and most of them follow an approach "based on a Human-Focused Design principles [sic], taking into account the person as the main goal of the design" [18].

The user-centered approach is underlined also by Nah et al. [19] who propose "a gamification framework to provide guidance and suggestions to software designers and researchers in gamifying their educational applications". Their framework is based on:

1. Principles of gamification, which are "(i) Goal orientation; (ii) Achievement, (iii) Reinforcement, (iv) Competition, and (v) Fun orientation" [19].

2. Game elements; such as: "points, levels, leaderboards, badges, onboarding, challenges/quests, and social engagement loop [...] feedback, teams/social dynamics, rules, marketplaces/economies, avatars, visual/3D space/sounds, customization, narrative context, and roleplay" [19].

\section{Dimensions of user's engagement.}

For Nah et al. [19] this framework is the mean to reach gamification aims. In their perspective the principal goals of gamification in the educational scenario "are to increase engagement as well as learning achievement" [19]. Interpreting engagement as "a state of deep attention and involvement" [19] that can be reached via the game elements listed above.

The picture drawn by the analysis of these conceptual contributions is the following: gamification is a technique positively influenced by different fields, such as marketing, human-computer interaction, game studies and design [20], and has several fields of application (such as: marketing, training, education, training, social networks) that registers a significant impact on numerous levels of human behavior [21].

There are several available frameworks for gamification design that "do not take into account some necessary keys to get a more effective gamified process for success" [18].

As far as the state of the art of gamification application and design is concerned, it lacks a "complete understanding of when gamification is an appropriate instructional tool and when it is not" [22].

Even if the concept and the definition of the term gamification is "gaining focus" and "initial frameworks based 
on foundational psychological theories, [...] have been collectively proposed" [23]; "empirical, mixed methods research that employs statistical analysis and reports effect sizes for standard elements, dynamics, and experiences" are needed [23].

These studies are fundamental to empirically validate the effects of gamification on users that were reported initially. "Likewise, comparative studies that employ controls are needed to ascertain what effects gamification has above and beyond other aspects of the system and in comparison to other approaches" [24].

To give a better understanding of the needs of empirical evidence in the field of gamification, the next section reports studies focused on this issue.

\section{Looking for empirical evidence in Gamification application}

From 2014 onwards several reviews of the literature, Hamari et al. [7]; Nah et al. [10]; Lister [25]; Thiebes et al. [26]; Pedreira et al. [17]; Dicheva et al. [27]; Dicheva \& Dichev [16] and Lumsden et al. [28], have been conducted with the purpose of investigating gamification empirical evidence.

Hamari et al. [11] focus on the analysis and empirical evidence of gamification as motivational affordance. By analyzing 24 articles they found that "gamification does work, but some caveats exist". In particular, the studies analyzed were for the majority qualitative and the few quantitative ones were lacking in methodological procedures, the experiments were of a limited number and not conducted with experimental methods.

Nah et al. [10], based on their literature review data, report that there are ten game design elements most frequently used in education: points; levels; strategies; badges; leaderboards; prizes; rewards; progress bar; storyline and feedback [10]. Based on 14 studies, they clarify the state-of-the-art related to the application of gamification in education. They conclude by encouraging "practitioners and researchers to use a design science approach to evaluate the impact of gamification in education" [10].

Lister [25] performed a literature review with the purpose of determining "to what extent gamification supports student achievement and motivation among college level students", finding that a gamified-based approach directed to postsecondary students in school environment affects students' motivation and supports students' achievement. 19 articles were found and in the conclusions a need for a study focus on "the impact of gamification on student academic success and performance" and further analysis on the weakness of gamification is pointed out [25].

Thiebes et al. [26] focus thir study on identifying the dynamics and mechanics used to enhance information systems (IS) users' performance and motivation, with a classification of the main mechanics and dynamics used in gamification. By analyzing 34 studies, they identified gamification as a promising approach to be applied in IS and to motivate users. They conclude by underlining the importance of investigating "the potential risks of gamification" [26].

Pedreira et al. [17] performed a systematic literature review aiming at drawing the state-of-the- art of applied gamification in the field of software engineering (SE). Based on 29 studies they pointed out that the use of gamification in SE is still at the beginning ("the field is quite preliminary"). "The adoption of gamification in SE is going more slowly than in other domains such as marketing, education, or mobile applications" [17]. Indeed, the game mechanics used are rather simple and limited to elements such as badges and points. Also, the application of gamification in the field of SE is in need of empirical support.

Studies such as Dicheva et al. [27] and Dicheva \& Dichev [16] report on a different domain but draw similar conclusions. Dicheva et al. [27] performed a systematic mapping study with the purpose of giving a complete overview of the empirical research done with respect to gamification in education. Dicheva et al., [27] analyzed 34 articles. The scenario pictured from their findings confirms what Hamari et al. [7] reported, that is: even if the number of publications on the use of gamification in education increased, the field suffers from (1) a lack of "true empirical research on the effectiveness of incorporating game elements in learning environments" [27]; and (2) inadequate "methodology used in most of the empirical settings to test the effects of the game elements", hampering a meta-analysis of the results [27].

In the follow-up study conducted by Dicheva \& Dichev [9], 41 articles were analyzed and the conclusions confirmed the previous literature review conducted.

The need for empirical analysis and further investigation about the effect that specific game elements generate in users is also raised by Lumsden et al. [28], and their studies with a more psychological focus in the field of cognitive training and assessment (testing). Based on 33 studies they have found promising results, but due to "heterogeneous study designs and typically small sample sizes" they highlighted "the need for further research in both gamified training and testing" fields [28].

In summary, this section shows that empirical evidence of effects of gamification has been investigated in several fields: education in general, [9], [27], [10]; at post-secondary level education, [25]; software engineering, [17]; cognitive training and assessment, [28] and as motivational affordance, [11]. Gamification is known for having motivational potential, offering engaging approaches and strategies to increase users' participation. However, this assumption requires more empirical data to cover gamification in its full variety and complexity.

The fact that empirical studies are needed "does not mean that gamification cannot be used with success in learning contexts. It simply means that the educational benefits of gamification have not been scientifically confirmed yet" [16]. Besides gamification "effects are greatly dependent on the 
context in which the gamification is being implemented, as well as on the users using it" [7].

As a consequence, designing gamification is not an easy practice; it requires a deep knowledge of the problem to be addressed.

With this purpose of giving a deeper understanding of the problem that we want to address using a gamified approach, section III is dedicated to MOOCs, their origin, and definition, as well as their drawbacks with a particular focus on the problems related to goal achievement and completion rates.

\section{MOOCS}

\section{A. MOOC definition}

The phenomenon of massive open online courses (MOOCs) appeared in 2008 and peaked almost in parallel to gamification: 2012 was declared the year of MOOCs [29]. MOOCs are modern educational opportunities, which use the Internet to scale up in participants and to reach massive audiences [1]. The acronym MOOC was coined by Dave Cormier and Bryan Alexander to describe the "Connectivism and Connective Knowledge" (CCK08) course launched by Stephen Downes and George Siemens at the University of Manitoba in 2008 [2].

\section{B. The problem we want to address in MOOCs}

High dropout and low completion rates are strongly presented in the literature as MOOCs' drawbacks. Recent studies suggest looking at completion rate as an expression of MOOC learners' intention [30] [3]. In the literature, the idea has been proposed that completion rates in MOOCs should be viewed in the light of user intention. Until now the success of a course has been measured in terms of completion, counting each participant who has not completed the course and its tasks and exams as drop out.

We argue that studying completion in MOOCs requires a different perspective. MOOCs are not traditional courses. The fact that they potentially can reach a massive number of people means that they can reach an enormous variety of needs. In this perspective, the user interest and intention have to be considered.

The reason why users stop following a MOOC may be due to a variety of reasons: they might not have been interested in completing the course and they were just "zapping" among the MOOCs, picking selected contents of interest.

By considering the massive audience that approaches a MOOC, it is most likely that not all the users who register for a MOOC have the intention to actually complete it. Our idea is to give the chance to all MOOC users to plan their personal learning goals and then support goal achievement via selected gamification means. In this way, the completion rate will not be the primary data for measuring MOOCs' success but learner-personal goal achievement.
One of the first studies in the field of Open Education that was looking at MOOCs from the users' intention perspective was that by Reich [3], [31]. Reich [3] conducted a pre-course survey study (response rate 28\%) delivered to HarvardX learners, aimed at investigating the MOOC users' intention regarding their MOOC participation, represented in figure 1.

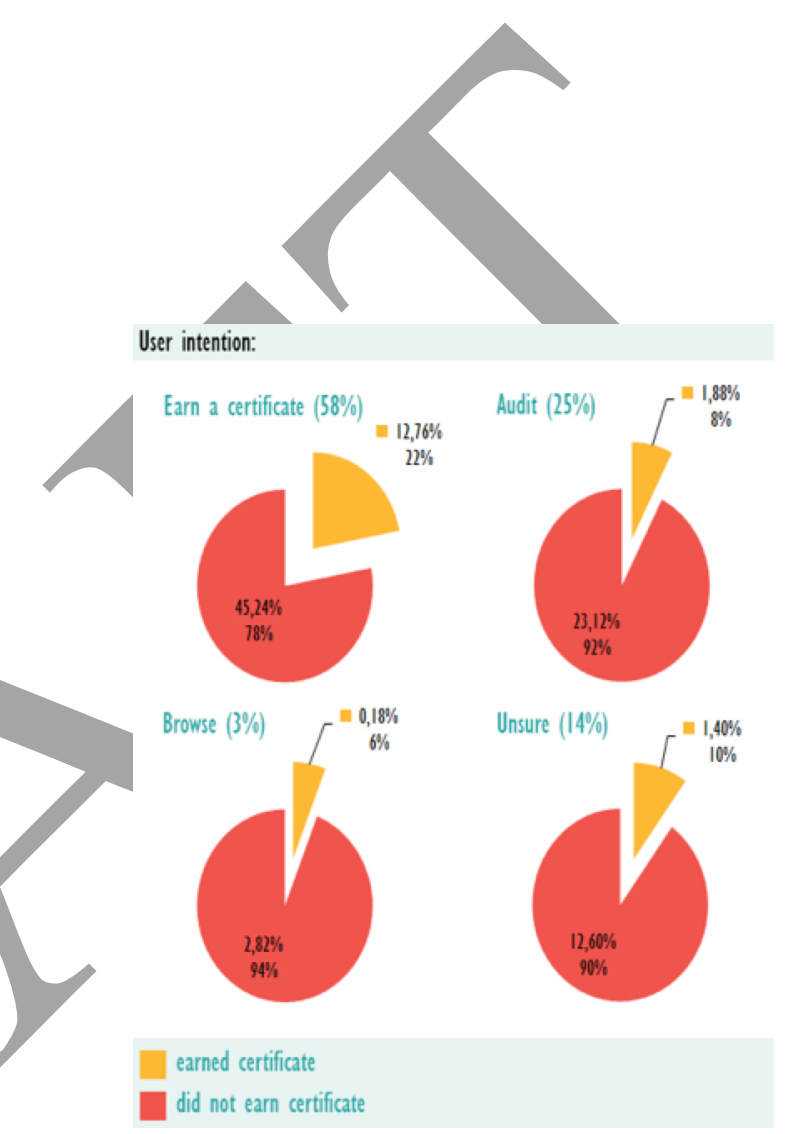

Fig. 1. Fig. 1. Graphic representation of Reich's survey with \% corresponding to the absolute (100\%) and relative (per group) values

The findings show that the intentions were different: $58 \%$ of the respondents "intended to earn a certificate" by reaching the end of the course. The remaining responding MOOC participants were distributed as follows: $25 \%$ "intended to audit" the MOOC, 14\% were "unsure" about their intentions, and 3\% declared that they "intended to browse" the MOOC.

Reich's survey data reveals on the one hand that those users who state to "intend to earn a certificate" show a higher completion rate compared to those who declare to "browse the MOOC", in agreement with the implementation intention theory. On the other hand, the data reveals that of the number of MOOC learners that declare the intention to earn a certificate, only $22 \%$ (of $58 \%$ ) achieved their goal, the rest $(36 \%)$ fails to do so. 
Consequently, these findings suggest an "intentionbehavior gap" for those remaining 36\%, which denotes the discrepancy between an intention and the action taken by a person [6]. While Gollwitzer's 'implementation intention' theory [5] states that by defining and using implementation intention, people point out "a specific plan that helps to promote the intention and efficient execution of goal-directed activity" [5].

The plan contains the "when", "where", and "how" of goal attainment in advance [32] and according to Gollwitzer [5] "when a goal intention is furnished with implementation intentions its chances of being accomplished increase. Interestingly, goal intentions that were not supplemented with implementation intentions showed rather low completion rates, suggesting that the realization of bare goal intention is easily stifled" [5].

"By planning, persons develop a mental representation of a suitable future situation ("when" and "where") and a behavioral action ("how"), which is expected to be effective for the goal pursuit to be performed in that situation" [6].

Considering that chances of goal achievement are high for people that plan their goal intention (e.g., to earn a certificate) with implementation intention, our purpose is to find game elements to be inserted in MOOCs to help users to implement their intentions within the MOOC environment.

Before explaining how we intend to implement our idea, some examples of gamified MOOCs are described in the next section for a better understanding of the state-of-the-art of gamification applied in MOOCs and of relevant differences.

\section{EXAMPLES ON GAMIFIED MOOCS}

With the purpose of providing an alternative approach and solution to the limits of MOOC design. several ways to combine MOOCs with gamification have been proposed by Gené et al. [33]; Tan [34], [35]; Willems et al. [36]; BorrasGene et al. [37]; Chauhan et al. [38]; Saraguro-Bravo et al. [38]; Mesquita et al. [39]; and Krause et al. [40].

Gené et al. [33] propose a new design model for MOOCs, called gcMOOC (gamification cooperative MOOC), that integrate gamification and virtual communities, such as Google + [33]. During the course that was implemented on the "Miriada X platform", two live interventions were provided. One via Google Hangouts (with registrations available on a YouTube channel), and the other via Instagram, with the assignment of posting two photos that were scored by the other participants (peers) via Google+ [33].

The aims pursued by Gené et al. [33] were "to promote cooperation, motivation and collaboration in MOOCs" among users via the "incorporation of elements of gamification" [33]. With the purpose of affecting "the participation, commitment and loyalty of students that may end in a greater number of proactive participants" [33].
The gamification elements introduced were: badges and competition. Badges were not delivered automatically by the platform but consisted in the form of participation certificates that could be "exported like badges inside the frame of the project Mozilla Open Badges" [33]. The competition element could be linked to the Instagram contest, but this was not further specified by the authors.

However, they presented the results of the implementation of their gcMOOC on Borras-Gene, Martinez-Nuñez, and Fidalgo-Blanco [37], to test the effect of gamification on the variables: collaboration, motivation, and cooperation, they claim to use a mixed method with qualitative and quantitative analyses. The tools used were surveys and semi-structured interviews, asking participants for feedback, and further quantitative data were acquired by tracking the number of new members in Googlet.

All in all, the structural empirical framework presented by Gené et al. [33] is not based on presented research results and thus, not convincing. Although a previous edition of the course without gamification elements is mentioned by the authors, a systematic comparative study is not presented.

The study further lacks a description of the game mechanics inserted in the MOOC and their functions. The elements of gamification presented seem to be restricted to badges and the use of the Google+ platform, and the badges were not always delivered by the platform due to technical issues.

In principle, the results seem largely based on the perception of users that were investigated via survey and semistructured interviews; no summative and formative studies with control groups were reported to systematically test the effects of the game mechanics inserted in the new platform [37].

Tan [34] explained his idea about a game MOOC by specifying his intention of creating a game, the architecture of this possible game MOOC is also presented with levels, challenges and tasks per each level, characterized by a linear process.

"Formal elements" (players, rules, outcomes, procedures, resources, conflict and boundaries) and "dramatic elements" (play challenge, premise, characters, and story) of a MOOC are listed. The author used the categories of a game to describe and show that a MOOC contains the same elements that could be found in a game [34]. This theoretical comparison is not translated and further developed in a game MOOC prototype.

The same author, Tan [35], in another article proposes a structural analysis of the similarity between a specific type of game: MMOG (Massive Multiplayer Online Game) and MOOC.

Following the line of the previous article, Tan underlines that MOOCs as MMOG have players, called users or learners, objectives, rules, (learning) resources, procedure, conflicts (for the authors the tests), (course) boundaries and outcomes. Concluding with some guidelines on the elements to be stressed when a MOOC is designed as MMOG. 
To some degree, we agree with Tan [35] in comparing MOOCs and MMOGs. However, the authors do not consider many differences between MOOC and MMOG phenomena, such as, among others: time spent in the environment and the sense of community they generated [39]. However, the ideas formulated by this author do not follow up with implementation and empirical study phases.

Another conceptual paper on the gamification of a MOOC platform is presented by Willems et al. [36]. They presented several game elements, usually used in gamification (points, levels, badges etc.) and listed the potential of their use in an online, massive environment. Focusing in particularly on the "rewarding system [...] balanced for different player types".

The authors also highlighted three main problems in MOOCs: dropout rate, the low tendency in using forum by MOOC users and the "peak of performance" in conjunction with the deadline. Issues that for Willems at al. [36] could be solved by the development of extrinsic motivation (dropout); investing on "user acceptance" (use of forum) and by making the users' effort continuous over time (peak of performance) [36].

Nevertheless, their conceptual idea is not yet being tested in "a system with a massive group of users in a production environment", therefore is lacking evidence about the efficacy of the gamification design on a large scale [36].

Chauhan et al. [38] present a conceptual idea to enhance personalization in MOOCs by using Augmented Reality (AR), Adapting Learning (AL) and Gamification as strategy. All three methods mentioned above are identified as potential solutions to the stated problem, but these authors do also not provide any empirical evidence to back up their claims [38]. As the authors express in the conclusion they indeed aim to combine these three approaches to study the effect on MOOC users' completion rate and motivation, however examples of this are not provided, neither a description of the game mechanics they are willing to use, nor the role of AR.

Theoretical ideas on the application of gamification in MOOCs are developed by Saraguro-Bravo et al. [40]. The authors propose a focus on MOOC participants' profiles for designing game mechanics that could enable users' motivation and learning performance enhancement. Mesquita et al. [41] present BrasiEduca, an Open Source MOOC platform, and their idea of integrating game elements (such as badges, achievements and rankings) to foster user motivation and engagement.

Krause et al. [42] follow a different approach: they set up an experiment. The authors conducted a systematic analysis with the purpose of studying how social gamification effects students' retention and learning success. They set up four conditions for their experiment (plain - no game element; game - with game elements; social - with social game elements). They implemented an online course directed to "lecturers of graduate and undergraduate courses in computer science (human-computer interaction) and psychology promoted the course in their lectures as a valuable addition".
As far as the experimental detail is concerned, the following game elements are implemented into the learning platform: badges, points, leaderboards, and time limits. Additionally, all students had the chance to personalize their own avatars that look like well-known Lego characters.

While in the social-game condition all the elements listed above were included and integrated with social game elements consisting of encouraging competition among students.

Their assumptions underlying in this study were mainly that gamification would affect students' learning success and retention and that the social game condition will amplify effects on both the variables: learning success and retention [42].

The data shows that participants' retention was affected by gamification. Indeed, students' retention was increased by $25 \%$ compared to the plain condition. "As predicted, the social game condition amplified the effect of the gamified condition, the students' retention in this case increase by $55 \%$ compared to plain" [42].

Students in the social game condition were more successful in learning compared to the plain condition, they "showed an even stronger increase of almost $40 \%$ compared to students in the plain condition" [42].

Hence, social gamification and its elements enhanced gamification condition effects on students' retention and success, showing to be more effective.

To sum up this section, several conceptual papers were presented to illustrate different ideas on how a MOOC could be boosted by the use of gamification.

Only the last example reported about an experiment aimed at investigating the empirical effects of a gamified MOOC on users.

From all the others examples, a common denominator is the request of empirical studies that will further study the effects of gamification on users' behaviors. It will be desirable to identify and map game elements and the effects they produce on a determinate population and environment.

Our idea, which will be further detailed in the next section, is to use gamification, and in particular, game mechanics to foster implementation intention planning and to enhance the chance of goal achievement by MOOC users.

\section{HOW TO ADDRESS MOOC USER GOAL ACHIEVEMENT WITH GAMIFICATION?}

Through the analysis of Reich's [3], [31] data, we have shown that by using the MOOC user intention lens, it is possible to look at MOOC completion rate from another perspective. So far completion rate has been measured as the number of people registered to a MOOC divided by the number of people who arrived at the end by earning a certificate. This calculation originates from a traditional way of measuring the 
completion of a course, but is not applicable to MOOC-based learning, because it does not consider the massive audience and the massive numbers of needs (intentions) they bring with them by approaching a MOOC.

MOOCs are not traditional courses and their quality and design are different [43]. That means: MOOCs do not necessarily need to be completed to be considered successful. However, they need to be designed carefully and in such a way that users can reach their goals.

In the traditional way of measuring the completion rate of a course it was calculated as the number of people completed the course $\left(\mathrm{n}_{\text {com }}\right)$ divided by the number of people registered $\left(\mathrm{n}_{\mathrm{reg}}\right)$.

Traditional Completion Rate definition:

$$
C R=\left(n_{\text {com }} / n_{\text {reg }}\right)
$$

With our aim to personalize this view, we introduce new measures: the Personal Goal Achievement Ratio (PGAR) and the Overall Goal Achievement Ratio (OGAR). PGAR is defined as the Personal Completion Ratio (PCR, i.e. the percentage of the course completed by the user) divided by the User Intention Ratio (UIR, i.e. the percentage of the course intended to be completed by the user). The OGAR is defined as the mean of all PGAR values for all registered users.

$$
\begin{gathered}
P G A R=(P C R / U I R) \\
O G A R=1 / n * \sum(P G A R)
\end{gathered}
$$

Based on implementation intention theory and data which shows "people who furnish their goal intention with implementation intention should be comparatively more successful in goal achievement" [5], our strategy is to find game elements that would allow users to achieve their goal via the act of planning their intentions.

The sources we want to use to find the most suitable game elements are: review of the literature; the collection of game design patterns (GDPs) from Björk and Holopainen [44] and the game design experts' feedbacks, as represented in Figure 2. By investigating three sources we aim to have a more comprehensive selection approach on the game elements needed and available for our purpose.

"The Design Patterns is a method of codifying design knowledge in separate but interrelated parts and has been used to describe game elements related to interaction" [45].

The GDP-based approach was not originally conceived for educational purposes but it has been used for educational purposes in Serious Games [46] and Mobile Games [47]. Using a GDP approach means drawing from a list of GDPs the most suitable one for the application scenario in which they will be embedded, in our case a MOOC.

In the work of Björk \& Holopainen [44] more than 200 GDPs are listed, categorized and described, each GDP constitutes an essential element of the building box of a game and is presented with the following details: name; description; consequences (for the application of it); ways of using the pattern (where the common choices made by game designer are presented) and relation with other patterns.

Having our main purpose in mind (i.e. enhancing goal achievement in MOOC users), we conducted a preliminary selection of GDPs choosing the most appropriate ones based on their descriptions and categorizations. This resulted in a list of 31 GDPs.

From the literature review, referring to Nah et al. [10] and the most recent work of Dicheva et al. [27], we extracted nine out of these 31 GDPs identified as the most used game elements in education. These are already detailed in section II (Points, Levels, Badges, Leaderboards, Prizes and Rewards, Progress Bars, Storyline and Feedback). The remaining 22 GDP are added based on their assumed relation to goal achievement.

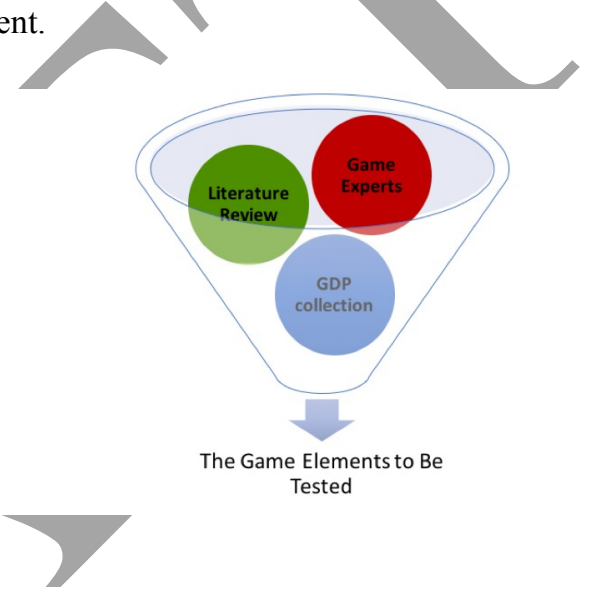

Fig. 1. Game elements selection process representation

As next steps, we aim to validate the selected game elements and implement them in a MOOC environment. We also plan to conduct two study types. First formative studies in order to tests usability and users' preferences. Secondly experimental studies where we will analyze the game design patterns on the MOOC users' performance in terms of goal achievement. This to determine and analyze the mediate effects of the game patterns (if any).

\section{CONCLUSIONS AND FUTURE WORK}

In this article, gamification has been presented, referring briefly to its history and origin as well as to the several fields of application and influences to help us contextualize gamification itself.

Various frameworks developed in the literature, with the aim of guiding (in particular educators) towards gamification design activities, have been presented, highlighting that they lack empirical validation and important elements that would enable effective gamified processes [18].

We have analyzed and documented the need of more scientific studies and the requirement of reconsidering gamification not only as the mere transfer of game elements into a non-game scenario but also as a technique that implies 
transversal knowledge in both, game design and the application field (MOOCs).

If gamification is not developed and designed with respect to the problem to be solved and the population to be targeted, it may not work as expected. Gamification is not just a buzzword, but it requires a meaningful design to implement a successfully gamified MOOC [25].

Several study examples of conceptual approaches on how to gamify MOOCs were introduced in this article. Only one study reports an empirical experiment related to an online course. Thus, we conclude that gamification is seen as a promising technique for MOOCs, however the field is lacking of empirical studies and understanding on how gamification should be designed for a massive audience and to solve specific problems of MOOCs.

In particular none of the reported examples presents our vision on completion rate and idea of finding GDPs to foster the planning and the application of Gollwitzer's implementation intention theory [48].

Therefore, our upcoming works will be:

1. A systematic, comprehensive literature review aiming at analyzing studies conducted in the field of gamification used in several environments, giving the priority to online learning and especially MOOCs. The purpose will be to map the most used game design elements and in particular their effects. The negative effects will be also reported.

2. A focus group interview with game design experts will be conducted to gain information about their ideas related to the most suitable game elements for our purpose: enhance goal achievements of users by the act of planning.

3. A validation study with game design experts will be carried out with the purpose of supporting our selection of GDPs from the Björk \& Holopainen collection.

4. The same selection of GDPs will be evaluated by instructional design (MOOC) experts to collect their ideas on the most suitable didactic approach to be followed and realized in our MOOC.

5. Successively we will conduct a study aiming to find the most suitable platform to develop our MOOC that could embed the selected GDPs.

6. Finally, we will design and implement gamified MOOCs using GDPs to test and analyze them with formative and summative studies.

Following the plan mentioned above, we aim to also prove that looking at completion rate in MOOCs from the perspective of users' intentions will change the evaluation, its results as well as consequently the recognition and reputation of MOOC.

MOOCs have to be treated differently from traditional courses: MOOCs do not require their full completion like traditional courses to be considered as successful. With this premise, their design has to take into consideration the individual user goals and enable users to foster their achievement. It implies to design and set up the MOOC in a way that freedom of choice and planning as well as the chance to declare their goals are enabled for learners, in accordance with the basic game design principles.

\section{ACKNOWLEDGMENT}

This project is supported by MOOQ, the European Alliance for Quality of Massive Open Online Courses (www.MOOCquality.eu). The vision of $\mathrm{MOOQ}$ is to foster quality in MOOCs leading to a new era of learning experiences.

MOOQ is co-funded by the European Commission under the project number: 2015-1-NL01-KA203-008950.

\section{[1] R. F. Kizilcec, C. Piech, and E. Schneider, "Deconstructing Disengagement: Analyzing Learner Subpopulations in Massive Open Online Courses,' Lak'13, 2013, p. 10.}

[2] A. M. F. Yousef, M. A. Chatti, U. Schroeder, and M. Wosnitza, "What drives a successful MOOC? An empirical examination of criteria to assure design quality of MOOCs," 14th IEEE Int. Conf. Adv. Learn. Technol. ICALT 2014, 2014, pp. 44-48.

[3] J. Reich, "Learner Intention Recasts 'Low' MOOC Completion Rates | HarvardX," 2014. [Online]. Available: http://harvardx.haryard.edu/news/learner-intention. [Accessed: 29-Feb2016].

[4] S. Deterding, D. Dixon, R. Khaled, and L. Nacke, "From Game Design Elements to Gamefulness: Defining 'Gamification,"' Proc. 2011 Annu. Conf. Ext. Abstr. Hum. factors Comput. Syst. - CHI EA '11, 2011, p. 2425.

[5] P. M. Gollwitzer, "Goal Achievement: The Role of Intentions," Eur. Rev. Soc. Psychol., vol. 4, no. 1, pp. 141-185, Jan. 1993.

F. F. Sniehotta, U. Scholz, and R. Schwarzer, "Bridging the intentionbehaviour gap: Planning, self-efficacy, and action control in the adoption and maintenance of physical exercise," Psychology and Health., vol. 20, no. 2, 2005, pp. 143-160.

[7] J. Hamari, J. Koivisto, and H. Sarsa, "Does gamification work? - A literature review of empirical studies on gamification," Proc. Annu. Hawaii Int. Conf. Syst. Sci., 2014, pp. 3025-3034.

[8] S. Nepal, C. Paris, and S. Bista, "Gamification on the Social Web," in Social Media for Government Services, S. Nepal, C. Paris, and D. Georgakopoulos, Eds. Cham: Springer International Publishing, 2015, pp. 197-220.

[9] Nick Pelling, "The (short) prehistory of "gamification", Funding Startups (\&amp; other impossibilities)," Heattu, 2011. [Online]. Available: https://nanodome.wordpress.com/2011/08/09/the-shortprehistory-of-gamification/.

[10] F. F. Nah, Q. Zeng, V. R. Telaprolu, A. P. Ayyappa, and B. Eschenbrenner, "Gamification of Education: A Review of Literature," in International Conference on HCI in Business 2014, 2014, pp. 401409.

[11] A. Mazarakis, "Using Gamification for Technology Enhanced Learning : The Case of Feedback Mechanisms," Bull. IEEE Tech. Comm. Learn. Technol., vol. 17, no. 4, 2015, pp. 6-9.

[12] M. D. Dickey, "Game design narrative for learning: Appropriating adventure game design narrative devices and techniques for the design of interactive learning environments," Educ. Technol. Res. Dev., vol. 54, no. 3, 2006, pp. 245-263. 
[13] S. Iqbal, X. Zang, Y. Zhu, Y. Y. Chen, and J. Zhao, "On the Impact of MOOCs on Engineering Education," in MOOC, Innovation and Technology in Education (MITE), 2014 IEEE International Conference on, 2014, pp. 101-104.

[14] B. S. Akpolat and W. Slany, "Enhancing software engineering student team engagement in a high-intensity extreme programming course using gamification," 2014 IEEE 27th Conf. Softw. Eng. Educ. Training, CSEE T 2014 - Proc., 2014, pp. 149-153.

[15] F. Bellotti, R. Berta, A. De Gloria, E. Lavagnino, A. Antonaci, F. Dagnino, M. Ott, M. Romero, M. Usart, and I. S. Mayer, "Serious games and the development of an entrepreneurial mindset in higher education engineering students," Entertain. Comput., vol. 5, no. 4, 2014, pp. 357366.

[16] D. Dicheva and C. Dichev, "Gamification in Education: Where Are We in 2015?," in E-Learn 2015 - Kona, Hawaii, United States, 2015, no. July 2014, pp. 1445-1454.

[17] O. Pedreira, F. García, N. Brisaboa, and M. Piattini, "Gamification in software engineering - A systematic mapping," Inf. Softw. Technol., 2015, vol. 57, no. 1, pp. 157-168.

[18] A. Mora, D. Riera, C. Gonzalez, and J. Arnedo-Moreno, "A Literature Review of Gamification Design Frameworks," in VS-Games 2015 - 7th International Conference on Games and Virtual Worlds for Serious Applications, 2015.

[19] F. F. Nah, V. R. Telaprolu, S. Rallapalli, and P. R. Venkata, "Gamification of Education Using Computer Games," in Lecture Notes in Computer Science (including subseries Lecture Notes in Artificial Intelligence and Lecture Notes in Bioinformatics), 2013, pp. 99-107.

[20] R. Tulloch, "Reconceptualising Gamification: Play and Pedagogy," Digit. Cult. Educ., 2014, vol. 6, no. December, pp. 317-333.

[21] K. Werbach, "(Re)defining gamification: A process approach," Lect. Notes Comput. Sci. (including Subser. Lect. Notes Artif. Intell. Lect. Notes Bioinformatics), 2014, vol. 8462 LNCS, pp. 266-272.

[22] R. N. Landers, K. N. Bauer, R. C. Callan, and M. B. Armstrong, "Psychological Theory and the Gamification of Learning," in Gamification in Education and Business, Cham: Springer International Publishing, 2015, pp. 165-186.

[23] K. Seaborn and D. I. Fels, "Gamification in theory and action: A survey," Int. J. Hum. Comput. Stud., 2014, vol. 74, pp. 14-31.

[24] O. Davidsson, J. Peitz, and S. Björk, "Game design patterns for mobile games," 2004.

[25] M. C. Lister, "Gamification: The effect on student motivation and performance at the post-secondary level," Issues Trends Educ. Technol., 2015,vol. 3, no. 2, pp. 1-22.

[26] S. Thiebes, S. Lins, and D. Basten, "Gamifying information systems A synthesis of gamifieation mechanics and dynamics," Twenty Second Eur. Conf. Inf. Syst., 2014, no. August 2016, pp. 1-17.

[27] D. Dicheva, C. Dichev, G. Agre, and G. Angelova, "Gamification in Education: A Systematic Mapping Study Gamification in Education: A Systematic Mapping Study,” Educ. Technol. Soc., 2015, vol. 18, no. June, pp. 75-88.

[28] J. Lumsden, E. A. Edwards, N. S. Lawrence, D. Coyle, and M. R. Munafò, "Gamification of Cognitive Assessment and Cognitive Training: A Systematic Review of Applications and Efficacy," JMIR Serious Games, 2016, vol. 4, no. 2, pp. 1-14.

[29] L. Pappano, "The Year of the MOOC," The New York Times, 2012. [Online]. Available: http://www.nytimes.com/2012/11/04/education/edlife/massive-openonline-courses-are-multiplying-at-a-rapidpace.html?pagewanted=all\&_r=0. [Accessed: 02-Nov-2012].
[30] M. Kalz, K. Kreijns, J. Walhout, J. Castaño-Munoz, A. Espasa, and E. Tovar, "Setting-up a European Cross-Provider Data Collection on Open Online Courses," Int. Rev. Res. Open Distrib. Learn., 2015, vol. 16, no. 6, pp. 62-77.

[31] J. Reich, "MOOC Completion and Retention in the Context of Student Intent," Educase, 2014. [Online]. Available: http://er.educause.edu/articles/2014/12/mooc-completion-and-retentionin-the-context-of-student-intent. [Accessed: 29-Feb-2016].

[32] P. M. Gollwitzer and P. Sheeran, "Implementation intentions and goal achievement: A meta-analysis of effects and processes," Adv. Exp. Soc. Psychol., 2006, vol. 38, pp. 69-119.

[33] O. B. Gené, M. Mart, and Á. F. Blanco, "Gamification in MOOC: Challenges, Opportunities and Proposals for Advancing MOOC Model," in Proceedings of the 2nd International Conference on Technological Ecosystems for Enhancing Multiculturality, 2014, pp. 215-220.

[34] C. T. Tan, "Towards a MOOC game," Proc. 9th Australas. Conf. Interact. Entertain. Matters Life Death - IE '13, pp. 1-4, 2013.

[35] C. T. Tan, "MOOCs vs MMOGs," in Proceedings of the International Conference on Managing the Asian Century, 2013, pp. 319-326.

[36] C. Willems, N. Fricke, S. Meier, R. Meissner, K. a. Rollmann, S. Voelcker, S. Woinar, and C. Meinel, "Motivating the Masses - Gamified Massive Open Online Courses on Openhpi," EDULEARN14 Proc., 2014, pp. 4042-4052.

[37] O. Borras-Gene, M. Martinez-Nuñez, and Á. Fidalgo-Blanco, "New Challenges for the Motivation and Learning in Engineering Education Using Gamification in MOOC," Int. J. Eng. Educ., 2016, vol. 32, no. 1, pp. 501-512.

[38] J. Chauhan, S. Taneja, and A. Goel, "Enhancing MOOC with Augmented Reality, Adaptive Learning and Gamification," Proc. 2015 IEEE 3rd Int. Conf. MOOCs, Innov. Technol. Educ. MITE 2015, 2016, no. JANUARY 2015, pp. 348-353,

[39] J. McGonigal, Reality is broken: why games make us better and how they can change the world. Vintage, 2012.

[40] R. A. Saraguro-Bravo, D. I. Jara-Roa, and M. Agila-Palacios, "Technoinstructional application in a MOOC designed with gamification techniques," in 2016 3rd International Conference on eDemocracy and eGovernment, ICEDEG 2016, 2016, pp. 176-179.

[41] M. A. A. Mesquita, A. M. Toda, and J. D. Brancher, "BrasilEduca - An Open-Source MOOC platform for Portuguese speakers with gamification concepts," IEEE Front. Educ. Conf., 2014, pp. 446-449.

[42] M. Krause, M. Mogalle, H. Pohl, and J. J. Williams, "A Playful Game Changer: Fostering Student Retention in Online Education with Social Gamification," in Proceedings of the 2nd ACM Conference on Learning @ Scale (L@S'15), 2015,pp.95-102.

[43] C. M. Stracke, "Openness for learning quality and change by Open Education in theory and practice - Overview, history, innovations and policies: How can Open Learning, OER and MOOCs achieve impact for learners, organizations and in society?," in Utopias and Dystopias in Education, In Press, 2016, pp. 1-29.

[44] S. Björk and J. Holopainen, Patterns in Game Design. 2005.

[45] A. Antonaci, R. Klemke, and M. Specht, "Towards Design Patterns for Augmented Reality Serious Games," Springer International Publishing, 2015, pp. 273-282.

[46] S. Kelle, R. Klemke, and M. Specht, "Design patterns for learning games," Int. J. Technol. Enhanc. Learn., 2011, vol. 3, no. 6, pp. 555569.

[47] B. Schmitz, "Mobile Games for Learning: A Pattern-Based Approach," Open University, 2014.

[48] P. M. Gollwitzer, "Implementation intentions," Am. Psychol., 1999, vol. 54, no. 7, pp. 493-503. 